\title{
Follow-up of aphakic patients with anterior vitrectomy in one eye and uneventful cataract extraction in the fellow eye
}

\author{
D. LEONNARD MACBEATH AND ROBERT DAVID \\ From the Department of Ophthalmology, University of the Witwatersrand, Johannesburg, and \\ St John Eye Hospital, Baragwanath, Johannesburg, South Africa
}

SUMMARY Twenty patients had operations for bilateral cataract in 2 separate sessions, with uncomplicated extraction on one side and vitreous loss managed with anterior vitrectomy on the other. The cataracts, the type of surgery, and the postoperative treatment were identical in both eyes.

The differences between the 2 eyes were not statistically significant so far as the amount of astigmatism, final visual acuity, and peripheral anterior synechiae were concerned. The main difference was found to be the period of time the vitrectomised eyes remained red and uncomfortable as compared to the eyes with uncomplicated surgery.

Since cataract extraction replaced couching over 200 years ago vitreous loss has been the most dreaded complication-after expulsive haemorrhage - occurring during cataract surgery. The sequelae of this complication are not related to the amount of vitreous lost during the operation, and they can occur in cases in which only the anterior hyaloid membrane is ruptured without manifest outpouring of vitreous through the wound. These complications are due to 4 mechanisms (Jaffe, 1972): Direct contact of vitreous with other structures (cornea, filtration angle, etc.); incarceration of vitreous in the surgical wound; inflammation; and fibrosis of the residual vitreous.

In an effort to overcome the first 2 of these mechanisms (and consequently reduce the risk of the last 2) Maumenee (1957) described the technique of aspirating fluid vitreous through the pupil and sweeping away all vitreous strands from the wound. Kasner (1968) suggested the use of scissors to cut formed vitreous as it adheres to Weck cell sponges introduced through the pupil, while Gass (1970) recommended the combination of these 2 techniques.

Whichever method is employed, surgeons throughout the world perform anterior vitrectomy today in an attempt to minimise the postoperative complications of vitreous loss. Indeed, since anterior

Address for reprints: Dr Robert David, Department of Ophthalmology, Soroka Medical Centre, Ben Gurion University, Beer Sheba, Israel vitrectomy has been used encouraging reports have appeared in the literature on the outcome of the eyes (Cerasoli and Kasner, 1971; Mazjna Miyake, 1972; Uchino, 1975; Luntz, 1977).

This study reports on the results of anterior vitrectomy performed on 1 eye of patients with bilateral surgery for cataracts who had an uneventful extraction in their fellow eye. This provided an objective comparison on the outcome of the 2 eyes of the same patient.

\section{Material and methods}

All patients with bilateral mature cataracts have their cataracts removed at an interval of 2 to 14 days between the 2 eyes. To ensure as much similarity as possible between the 2 eyes the patients had to meet the following requirements in order to qualify for this study: No other pre-existing unilateral eye disease; identical surgical approach to both eyes (i.e., corneal section or limbal section).

Patients with surgical complications such as capsule rupture were excluded from the study. The only exception were those patients who had vitreous loss and anterior vitrectomy in the first eye. In these cases surgery for the second eye was performed by a consultant and under general anaesthesia whenever possible.

Local anaesthesia was the rule. The incision was either limbal (under a conjunctival flap) with 9-0 virgin silk sutures, or a corneal section with 10-0 nylon monofilament sutures. An operating micro- 
scope was used in all cases. Chymotrypsin was used in patients under the age of 55 and the lens was delivered with the cryoextractor.

Whenever rupture of the anterior hyaloid membrane was encountered (with or without manifest bulk-loss of vitreous), anterior vitrectomy was performed by the technique described by Gass (1970).

Postoperative treatment was identical in both eyes-atropine and a steroid-antibiotic combination, both given as drops twice and four times daily for 4 to 6 weeks after surgery.

All patients were discharged from the hospital 7 to 10 days after the operation on the second eye and seen again 2, 4, 8, and 12 weeks after discharge. Thereafter follow-up was at 3-monthly intervals. On each visit the general appearance of the eyes was noted, corrected visual acuity was checked, keratometry was performed, and intraocular pressure measured, anterior chamber activity and pupil state were assessed, and finally indirect ophthalmoscopy (of the central and peripheral retina) and gonioscopy were performed.

Twenty patients met the above criteria and were followed up for a period of 6 months to 2 years. They represent the material for this report.

\section{Results}

There were 12 males and 8 females, their ages ranging from 53 to 89 . The follow-up time was from 6 months to 2 years (1 patient was followed up for 3 years), with an average of $10 \cdot 1$ months per case (Table 1).

Table 2 reflects the comparative results in both eyes of the 20 patients. Seventeen patients retained useful vision (6/60 or better); 2 of them had a visual acuity in the eye after vitrectomy better than in the fellow eye with uneventful extraction, and 2 others ended up with equal vision in both eyes. In 6 patients the visual acuity in the eye with uncomplicated extraction was better by only 1 line on the Snellen chart.

Seven patients had a higher astigmatism in the eye with vitrectomy and 2 patients in the uneventfully operated upon eye, while the other 11 had either an equal amount of astigmatism or an astigmatism of less than 1 dioptre.

The final visual acuity and the amount of astigmatism were submitted to statistical analysis. With Student's $t$ test no statistically significant differences could be found $(P>0 \cdot 1)$ between the 2 groups of eyes.

The pupil was peaked or irregular in 7 eyes after vitrectomy and in 2 eyes after uncomplicated cataract extraction, while peripheral anterior synechiae of
Table 1 Follow-up time-cataract extraction with vitrectomy

\begin{tabular}{ll}
\hline Months of follow-up & No. of cases \\
\hline 6 & 8 \\
9 & 3 \\
12 & 6 \\
18 & 2 \\
36 & 1 \\
Average time & $10 \cdot 1$ \\
\hline
\end{tabular}

$45^{\circ}$ or more were seen in 7 eyes after vitrectomy and in 3 of the eyes uneventfully operated on.

The main difference in the findings occurred in the posterior segment, where none of the straightforward operations developed any complications, while among the eyes after vitrectomy there were 2 patients with cystoid macular oedema, 3 others with vitreous opacities following haemorrhage, and 1 with retinal detachment which occurred 8 weeks after surgery.

Two patients developed glaucoma, in 1 patient complicated with bullous keratopathy which necessitated further surgery, but the patient did not regain useful vision. No cases of glaucoma were noted among the 20 eyes without vitrectomy.

In Table 3 it can be seen that, while the eyes without vitrectomy settled or had only slight discomfort 8 weeks after surgery, 7 eyes after vitrectomy still had mild to moderate irritation 3 months after surgery.

\section{Discussion}

The visual results in the eyes after vitrectomy in this report, though certainly inferior to those in the eyes not subjected to vitrectomy, compare favourably with the results quoted in the previous decade by Vail $(1965,1968)$ and more recently by Gardner (1975). The fact that Vail's patients were followed up for longer periods than ours cannot explain the difference in the results, as it is accepted that most of the complications attributed to vitreous loss occur during the first year after cataract surgery (Jaffe, 1972).

So far as the complications are concerned, it appears that cystoid macular oedema occurred less frequently in our patients than in other series (Cerasoli and Kasner, 1971; Gardner, 1975).

The final results in the anterior segment of the eyes with vitrectomy are quite satisfactory both in our and other authors' experience (Luntz, 1977; MacPherson, 1976). It is the posterior part of the eye where the major complications still occur, and 
Table 2 Final results in 20 patients with bilateral cataracts: uneventful surgery (U); anterior vitrectomy (V)

\begin{tabular}{|c|c|c|c|c|c|c|c|c|c|c|c|c|c|c|}
\hline \multirow[t]{2}{*}{$\begin{array}{l}\text { Case } \\
\text { no. }\end{array}$} & \multicolumn{2}{|c|}{$\begin{array}{l}\text { Amount of } \\
\text { astigmatism }\end{array}$} & \multicolumn{2}{|c|}{ Visual acuity } & \multicolumn{2}{|c|}{ Pupil shape } & \multicolumn{2}{|c|}{$A C$ angle } & \multicolumn{2}{|c|}{ Fundus } & \multicolumn{2}{|c|}{$I O P$} & \multicolumn{2}{|l|}{ Remarks } \\
\hline & $\mathrm{U}$ & $\mathrm{V}$ & $\mathrm{U}$ & $\mathrm{V}$ & $\mathbf{U}$ & $\mathrm{v}$ & $\mathbf{U}$ & $\mathbf{v}$ & $\mathbf{U}$ & $\mathrm{v}$ & $\mathbf{U}$ & $\mathrm{V}$ & $\mathbf{U}$ & $\mathrm{v}$ \\
\hline 1 & $1 \cdot 0$ & $1 \cdot 0$ & $6 / 5$ & $6 / 24$ & $\mathbf{R}$ & $\mathbf{P}$ & $\mathbf{N}$ & $\mathbf{N}$ & $\mathbf{N}$ & $\begin{array}{l}\text { Cystoid } \\
\text { macular } \\
\text { oedema }\end{array}$ & $\mathbf{N}$ & $\mathbf{N}$ & - & - \\
\hline 2 & $1 \cdot 0$ & $1 \cdot 0$ & $6 / 5$ & $6 / 6$ & $\mathbf{R}$ & $\mathbf{R}$ & PAS & $\mathbf{N}$ & $\mathbf{N}$ & $\mathrm{N}$ & $\mathbf{N}$ & $\mathbf{N}$ & - & - \\
\hline 3 & $1 \cdot 0$ & $2 \cdot 5$ & $6 / 9$ & $6 / 18$ & $\mathbf{R}$ & $\mathbf{R}$ & $\mathbf{N}$ & PAS & $\mathbf{N}$ & $\mathbf{N}$ & $\mathbf{N}$ & $\mathbf{N}$ & - & - \\
\hline 4 & $1 \cdot 0$ & $2 \cdot 75$ & $6 / 7 \cdot 5$ & $6 / 60$ & $\mathbf{R}$ & $\mathbf{R}$ & $\mathbf{N}$ & $\mathbf{N}$ & $\mathrm{N}$ & $\mathbf{N}$ & $\mathbf{N}$ & $\mathbf{N}$ & - & $\begin{array}{l}\text { Opaque vit. } \\
\text { haem. }\end{array}$ \\
\hline 5 & $1 \cdot 0$ & $1 \cdot 0$ & $6 / 9$ & $6 / 18$ & $\mathbf{R}$ & $\mathbf{R}$ & $\mathbf{N}$ & $\mathbf{N}$ & $\mathbf{N}$ & $\begin{array}{l}\text { Cystoid } \\
\text { macular } \\
\text { oedema }\end{array}$ & $\mathbf{N}$ & $\mathbf{N}$ & - & - \\
\hline 6 & 1.0 & $1 \cdot 0$ & $6 / 24$ & $3 / 60$ & $\mathbf{P}$ & $\mathbf{P}$ & PAS & PAS & $\mathbf{N}$ & No view & $\mathbf{N}$ & $\mathbf{N}$ & $\begin{array}{l}\text { Old corneal } \\
\text { leucoma }\end{array}$ & $\begin{array}{l}\text { Opaque vit. } \\
\text { haem. }\end{array}$ \\
\hline 7 & $1 \cdot 0$ & $1 \cdot 0$ & $6 / 9$ & $6 / 5$ & $\mathbf{R}$ & $\mathbf{P}$ & $\mathbf{N}$ & PAS & $\mathbf{N}$ & $\mathbf{N}$ & $\mathbf{N}$ & $\mathbf{N}$ & - & - \\
\hline 8 & $1 \cdot 0$ & $1 \cdot 5$ & $6 / 6$ & $6 / 7 \cdot 5$ & $\mathbf{R}$ & $\mathbf{R}$ & $\mathbf{N}$ & $\mathbf{N}$ & $\mathbf{N}$ & $\mathbf{N}$ & $\mathbf{N}$ & $\mathbf{N}$ & - & - \\
\hline 9 & $1 \cdot 0$ & $3 \cdot 0$ & $6 / 12$ & HM & $\mathbf{R}$ & $\mathbf{P}$ & $\mathbf{N}$ & PAS & $\mathbf{N}$ & No view & $\mathbf{N}$ & High & - & $\begin{array}{l}\text { Bullous } \\
\text { keratopathy }\end{array}$ \\
\hline 10 & $1 \cdot 25$ & $1 \cdot 0$ & $6 / 7 \cdot 5$ & $6 / 36$ & $\mathbf{P}$ & $\mathbf{P}$ & $\mathbf{N}$ & PAS & $\mathbf{N}$ & $\begin{array}{l}\text { Cupped } \\
\text { disc }\end{array}$ & $\mathbf{N}$ & High & - & - \\
\hline 11 & $1 \cdot 0$ & $1 \cdot 0$ & $6 / 6$ & $6 / 9$ & $\mathbf{R}$ & $\mathbf{R}$ & $\mathbf{N}$ & $\mathbf{N}$ & $\mathbf{N}$ & $\mathbf{N}$ & $\mathbf{N}$ & $\mathbf{N}$ & - & - \\
\hline 12 & $1 \cdot 0$ & $1 \cdot 5$ & $6 / 12$ & $6 / 15$ & $\mathbf{R}$ & $\mathbf{R}$ & $\mathbf{N}$ & $\mathbf{N}$ & $\mathbf{N}$ & $\mathbf{N}$ & $\mathbf{N}$ & $\mathbf{N}$ & $\begin{array}{l}\text { Pre-exist. } \\
\text { corneal } \\
\text { opacities }\end{array}$ & $\begin{array}{c}\text { Pre-exist. } \\
\text { corneal } \\
\text { opacities }\end{array}$ \\
\hline 13 & $1 \cdot 0$ & 1.0 & $6 / 12$ & $6 / 60$ & $\mathbf{R}$ & $\mathbf{R}$ & PAS & $\mathbf{N}$ & $\mathbf{N}$ & $\mathbf{N}$ & $\mathbf{N}$ & $\mathbf{N}$ & - & $\begin{array}{l}\text { Opaque vit. } \\
\text { haem. }\end{array}$ \\
\hline 14 & $1 \cdot 0$ & $1 \cdot 0$ & $6 / 12$ & HM & $\mathbf{R}$ & $\mathbf{R}$ & $\mathbf{N}$ & $\mathbf{N}$ & $\mathbf{N}$ & $\begin{array}{l}\text { Ret. } \\
\text { detach. }\end{array}$ & $\mathbf{N}$ & $\mathbf{N}$ & - & - \\
\hline 15 & $2 \cdot 0$ & $1 \cdot 5$ & $6 / 12$ & $6 / 9$ & $\mathbf{R}$ & $\mathbf{P}$ & $\mathbf{N}$ & PAS & $\mathbf{N}$ & $\mathbf{N}$ & $\mathbf{N}$ & $\mathrm{N}$ & - & - \\
\hline 16 & $1 \cdot 0$ & $1 \cdot 0$ & $6 / 9$ & $6 / 15$ & $\mathbf{R}$ & $\mathbf{R}$ & $\mathbf{N}$ & $\mathbf{N}$ & $\mathbf{N}$ & $\mathbf{N}$ & $\mathbf{N}$ & $\mathrm{N}$ & - & - \\
\hline 17 & 1.0 & $1 \cdot 0$ & $6 / 15$ & $6 / 15$ & $\mathbf{R}$ & $\mathbf{R}$ & $\mathbf{N}$ & $\mathbf{N}$ & $\mathbf{N}$ & $\mathbf{N}$ & $\mathbf{N}$ & $\mathbf{N}$ & $\begin{array}{l}\text { Pre-exist. } \\
\text { corneal } \\
\text { opacities }\end{array}$ & $\begin{array}{l}\text { Pre-exist. } \\
\text { corneal } \\
\text { opacities }\end{array}$ \\
\hline 18 & $1 \cdot 0$ & $1 \cdot 0$ & $1,1:$ & $6 / 12$ & $\mathbf{R}$ & $\mathbf{R}$ & $\mathbf{N}$ & $\mathbf{N}$ & $\mathbf{N}$ & $\mathbf{N}$ & $\mathbf{N}$ & $\mathbf{N}$ & - & - \\
\hline 19 & $1 \cdot 0$ & $1 \cdot 0$ & $6 / 9$ & $6 / 36$ & $\mathbf{R}$ & $\mathbf{P}$ & $\mathbf{N}$ & PAS & $\mathbf{N}$ & $\mathbf{N}$ & $\mathbf{N}$ & $\mathbf{N}$ & - & - \\
\hline 20 & $2 \cdot 0$ & 3.0 & $6 / 12$ & $6 / 15$ & $\mathbf{R}$ & $\mathbf{R}$ & $\mathbf{N}$ & $\mathbf{N}$ & $\mathbf{N}$ & $\mathbf{N}$ & $\mathbf{N}$ & $\mathbf{N}$ & - & - \\
\hline
\end{tabular}

$\mathbf{R}=$ Round. $\quad \mathbf{P}=$ Peaked. $\quad \mathbf{N}=$ Normal. $\quad$ PAS $=$ Peripheral anterior synechiae. $\quad \mathbf{H M}=$ Hand movements

Table 3 General appearance of eyes in first 12 weeks after operation

\begin{tabular}{|c|c|c|c|c|c|c|c|c|}
\hline \multirow{2}{*}{$\begin{array}{l}\text { Injection } \\
\text { photophobia } \\
\text { discomfort }\end{array}$} & \multicolumn{2}{|c|}{2 weeks } & \multicolumn{2}{|c|}{4 weeks } & \multicolumn{2}{|c|}{8 weeks } & \multicolumn{2}{|c|}{12 weeks } \\
\hline & $U$ & $\boldsymbol{V}$ & $U$ & $V$ & $U$ & $\boldsymbol{V}$ & $U$ & $\boldsymbol{V}$ \\
\hline 0 & 3 & -- & 8 & 1 & 14 & 2 & 16 & 8 \\
\hline+ & 7 & 2 & 6 & 7 & 6 & 8 & 4 & 5 \\
\hline++ & 6 & 9 & 5 & 6 & - & 6 & - & 6 \\
\hline+++ & 3 & 5 & 1 & 6 & - & 4 & - & 1 \\
\hline++++ & 1 & 4 & - & - & - & - & - & - \\
\hline
\end{tabular}

$+=$ Slight. ${ }^{++}=$Mild.
+++ there were differences there between the vitrectomy eyes and the eyes with uneventful cataract surgery.

Glaucoma was encountered in 2 eyes out of the 7 with peripheral anterior synechiae after vitrectomy but in none of the 3 eyes with peripheral anterior synechiae after uneventful cataract extraction. As peripheral anterior synechiae were found in $47 \%$ of uneventful cataract extractions (Racz et al., 1974) the glaucoma is probably not directly related to these synechiae in our 2 cases.

Vitreous opacity due to haemorrhage was the most frequent complication which affected 3 patients $(15 \%)$ in their vitrectomised eye. This complication, although quite common after vitreous loss (Jaffe, 
1972), is not reported among the complications in most of the follow-up studies on the outcome of anterior vitrectomy in the recent literature.

The main difference between the 2 eyes in this study was found in the length of time from operation and to when the eyes settled. Virtually all patients had a red eye and complained of discomfort in the eye with vitrectomy well after the fellow eye was already quiet and trouble-free. We attribute this to the prolonged vitritis which accompanies these cases.

There is no doubt in our minds that it is the routine use of the operating microscope for cataract surgery in general and anterior vitrectomy in particular which is responsible for the improvement in the fate of eyes with vitreous loss during surgery. Kasner (1973) wrote that 'The eye can get along without vitreous'. This is a rather strong statement. But, while the surgeon should make every effort to avoid loss of vitreous during cataract surgery, if this complication does occur the vitrectomy should be generous and performed with patience until the entire iris and pupil rest in a concave shape on the remnants of the vitreous. We agree with Gardner (1975) that if this regimen is followed there will be fewer peaked pupils too after vitrectomy.

We are grateful to Professor M. H. Luntz for his help and criticism, and to Mrs D. G. Livingston for help with the statistics.

\section{References}

Cerasoli, J. R., and Kasner, D. (1971). A follow-up study of vitreous loss during cataract surgery managed by anterior vitrectomy. American Journal of Ophthalmology, 71, 10401043.

Gardner, R. C. (1975). Anterior vitrectomy. Annals of Ophthalmology, 7, 723-726.

Gass, J. D. M. (1970). Management of vitreous loss after cataract. Archives of Ophthalmology, 83, 319-323.

Jaffe, N. S. (1972). Cataract Surgery and its Complications, pp. 124-127. Mosby: St. Louis.

Kasner, D. (1968). Vitrectomy: a new approach to the management of vitreous. Highlights of Ophthalmology, 11, 304-309.

Kasner, D. (1973). Vitreous loss during cataract surgery. Transactions of the American Academy of Ophthalmology and Otolaryngology, 77, 184-185.

Luntz, M. H. (1977). Indikation, technik und resultate der vorderen vitrektomie. Klinische Monatsblätter für Augenheilkunde, 170, 855-862.

McPherson, S. (1976). Management of vitreous loss after cataract extraction. In Advances in Ophthalmology, Vol. 33. Microsurgery of Cataracts, Vitreous and Astigmatism, pp. 172-174. Edited by D. Pierse and H. J. Kersley. Karger: Basel.

Maumenee, A. E. (1957). Symposium: Post-operative cataract complications III. Epithelial invasion of the anterior chamber, corneal edema, retinal detachment, anterior chamber hemorrhages, chages in the macula. Transactions of the American Academy of Ophthalmology and Otolaryngology, 61, 51-68.

Mazjna, Y., and Miyake, K. (1972). Anterior vitrectomy: indication in vitreous loss during lens extraction. Folia Ophthalmologica Japonica, 23, 22-26.

Racz, P., Szilvassy, I., and Pinter, E. (1974). The chamber angle after uneventful cataract extraction. Klinische Monatsblätter für Augenheilkunde, 164, 218-220.

Uchino, M. (1975). A follow-up study of vitreous loss after cataract extraction. Folia Ophthalmologica Japonica, 26, 479-482.

Vail, D. (1965). After results of vitreous loss. American Journal of Ophthalmology, 59, 573-586.

Vail, D. (1968). Loss of vitreous during cataract surgery. Highlights of Ophthalmology, 11, 107-119. 